\author{
МАЗУРКИН П.М' ${ }^{1}$, КУДРЯШОВА А.И ${ }^{2}$. \\ ${ }^{1}$ Доктор технических наук, ${ }^{2}$ Магистрант 2-го курса
}

Поволжский государственный технологический университет

\title{
ВОЛНОВАЯ ДИНАМИКА ОНТОГЕНЕЗА ЛИСТЬЕВ \\ ЗАГРЯЗНЕННОЙ ОКОЛО АВТОМОБИЛЬНОЙ ДОРОГИ ЛИПЫ
}

Аннотация. Даны волновые уравнения динамики онтогенеза листьев липь, растущей около автомобильной трассы с интенсивным движением. Показан способ анализа параметров (длинь, ииринь,, периметра и площади) для инженерной биологии и биоиндикащии окружающей воздушной среды колебательными возмущениями листьев. На обочине выбирают дерево и замеряют перпендикулярно дороге расстояние от середины корневой шейки до бордюра. Затем в кроне на удобной для измерений высоте выделяют зоны по сторонам света. В каждой зоне выбирают группу из не менее 5 учетных листьев, отмечаемые метками в виде кусков белой нитки, привязанных на черешке. Из измеренных не менее 10 раз в период вегетаџии данных выбирают параметры с максимальными значениями, относительно них совместно с периодом онтогенеза от распускания почек до опадения каждого учетного листа выполняют факторный анализ. По данным статистическим моделированием выявляют закономерности бинарных отношений.

Ключевые слова: листья, параметры, онтогенез, волны поведения

\author{
Mazurkin P.M ${ }^{1}$, Kudryashova A.I ${ }^{2}$. \\ ${ }^{1}$ Doctor of Technical Sciences, ${ }^{2}$ Master student the 2nd year \\ Volga State University of Technology \\ WAVE DYNAMICS ONTOGENESIS LEAF \\ CONTAMINANTS APPROXIMATELY LINDEN ROAD
}

Abstract. Given the dynamics of the wave equation ontogeny linden leaves growing near the highway with heavy traffic. Shows a method of analysis parameters (length, width, perimeter and area) for engineering biology and bio- 
indication to the ambient air-vibrational disturbances leaves. On the side of the tree is selected and replaced ryayut-perpendicular to the road distance from the middle of the root collar to the curb. Then in the crown at a comfortable height measurement zone is isolated to the cardinal. Each zone is selected from a group of at least 5 user leaves celebrated labels in the form of pieces of white thread, attached to the petiole. From the measured at least 10 times during the growing season data selected parameters with maximum values on them together with a period of ontogenesis bud to leaf abscission each accounting perform factor analysis. According to the statistical modeling show patterns of binary relations.

Keywords: leaves, options, ontogeny, wave behavior

\section{Сущность способа измерения}

Заключается в том, что от середины корневой шейки до примерного центра каждой из четырех локальных зон рулеткой измеряют расстояние по радиусу кроны от вертикальной оси ствола дерева, а миллиметровой линейкой высоты групп листьев от поверхности почвы. После этого с учетом угла наклона линии бордюра к северному направлению рассчитывают расстояния от дороги до вертикальной линии у каждой группы учетных листьев [1-5].

Сущность заключается также и в том, что за вегетационный период по суткам от начала распускания почек листьев до конца вегетационного периода (в день опадания каждого учетного листа) в периоде онтогенеза каждого учетного листа выполняют фотографирование через прозрачную палетку с сеткой 2 мм, а затем за период $T$ онтогенеза у каждого учетного листа принимают продолжительность времени с начала распускания почек до даты опадения каждого из учетных листьев.

Новизна технического решения заключается в том, что впервые рассматривается средняя динамика поведения групп из не менее пяти листьев липы, расположенных по сторонам света, в онтогенезе в зависимости от рас- 
стояния от края автомобильной дороги и высоты расположения каждой группы листьев над поверхностью почвы.

Положительный эффект заключается в том, что впервые точно можно выявлять закономерности динамики поведения за весь цикл онтогенеза группы учетных листьев по измеренным 20 учетным листам липы, а также по четырем группам листьев по максимальным параметрам учетных листьев.

\section{Методика измерений}

Опыты на дереве липы были проведены в городе Йошкар-Ола в вегетационный период 2014 г. на одних и тех же 20 учетных листьях липы, расположенной на стороне улицы Машиностроителей около перекрестка с улицей Красноармейской. Учетные листья выбирали в четырех локальных зонах по сторонам света.

По сторонам света выбирали по пять учетных листьев. Каждый учетный лист помечали меткой в виде куска белой нитки с биркой с номером листа, привязанной к черешку у основания листа. Номера листьям давали по часовой стрелке: 1-5 на северной стороне, 6-10 на восточной, 11-15 на южной и 16-20 на западной стороне света.

Способ измерения длины, ширины, периметра и площади у учетных листьев включает такие действия: на лист сверху кладут прозрачную палетку с сеткой, например, с малыми клетками размерами $2 \times 2$ мм, так, чтобы средняя линия вдоль палетки совпала с осью продольной жилки листа.

Затем лист с палеткой фотографируют, например, цифровым фотоаппаратом с функциями фотографирования и хранения множества фотоснимков в памяти. Перед измерениями у каждого листа нужно взять его фото и подрезать на компьютере кромки, а затем увеличить для удобства подсчетов клеток до формата A4.

\section{Результаты измерений}

В таблице 1 приведены результаты измерений (фрагмент) в онтогенезе от момента распускания почек всех листьев до момента опадения каждого 
учтенного листа. Эти данные необходимы для построения пространственных графиков динамики четырех основных параметров учетных листьев загрязненной березы (рис. 1) и последующего статистического моделирования динамики онтогенеза групп учетных листьев по сторонам света.

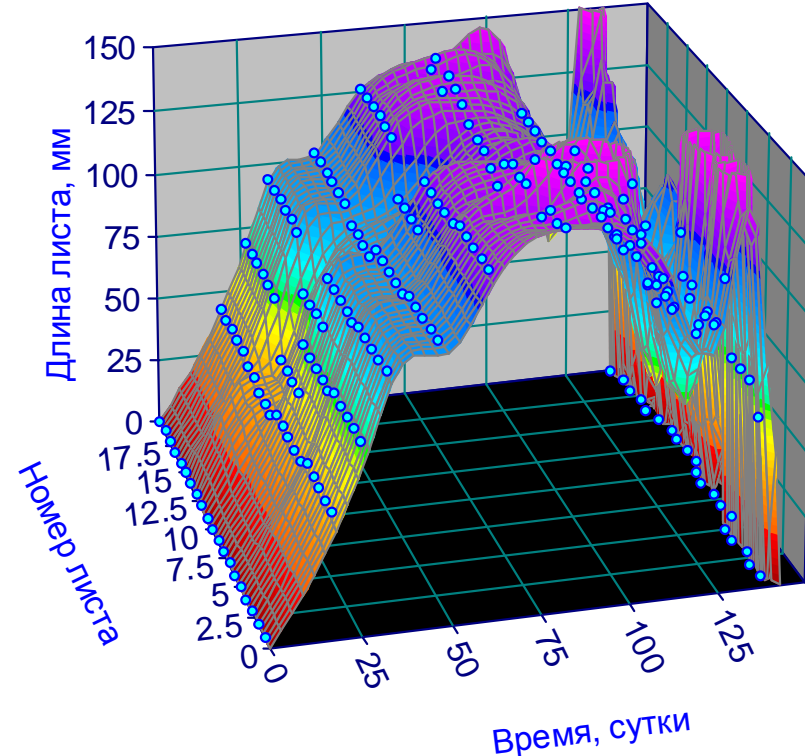

Длина листа, мм

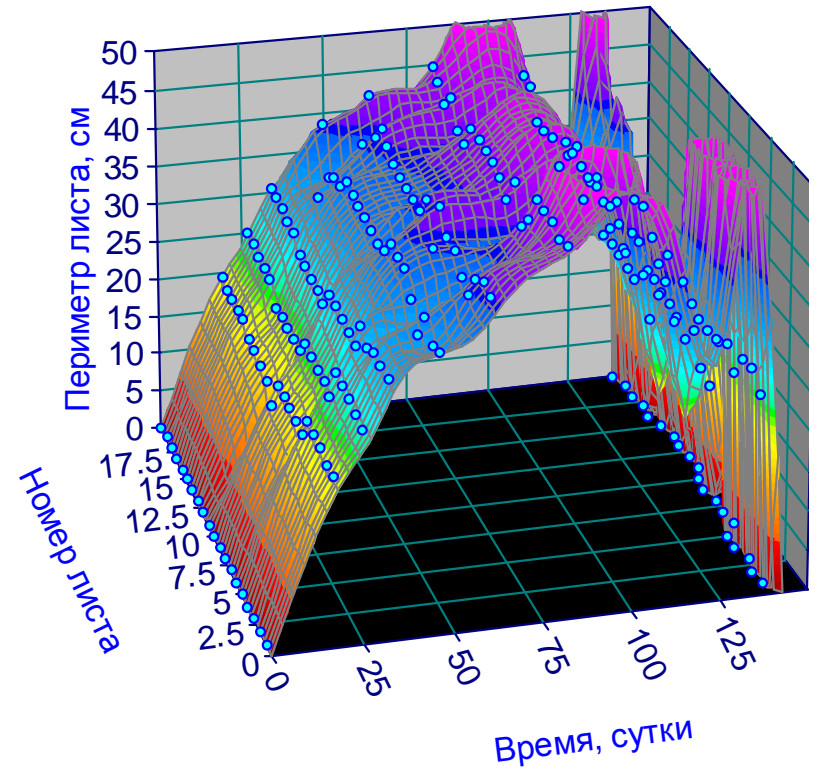

Периметр листа, см

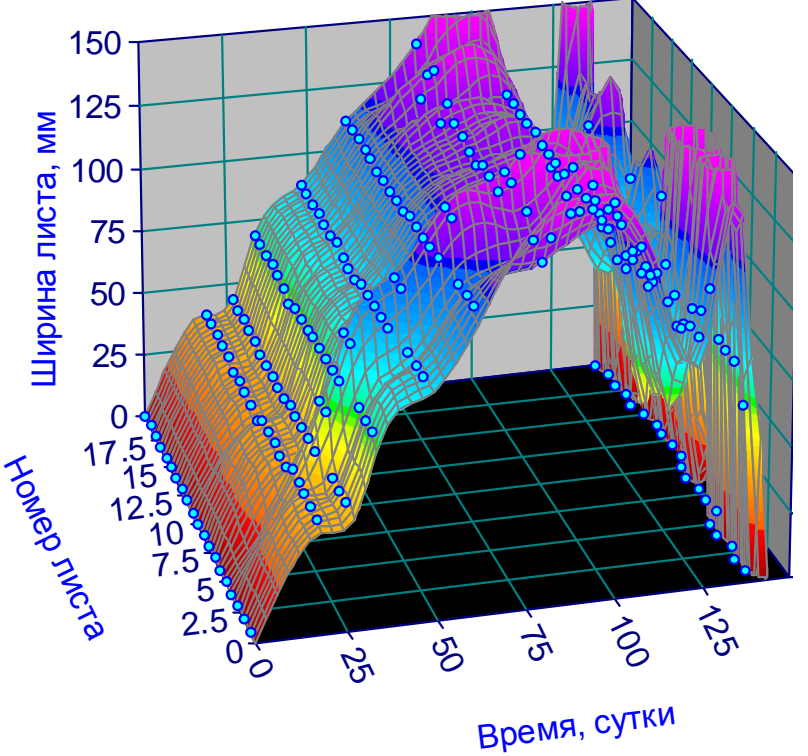

Ширина листа, мм

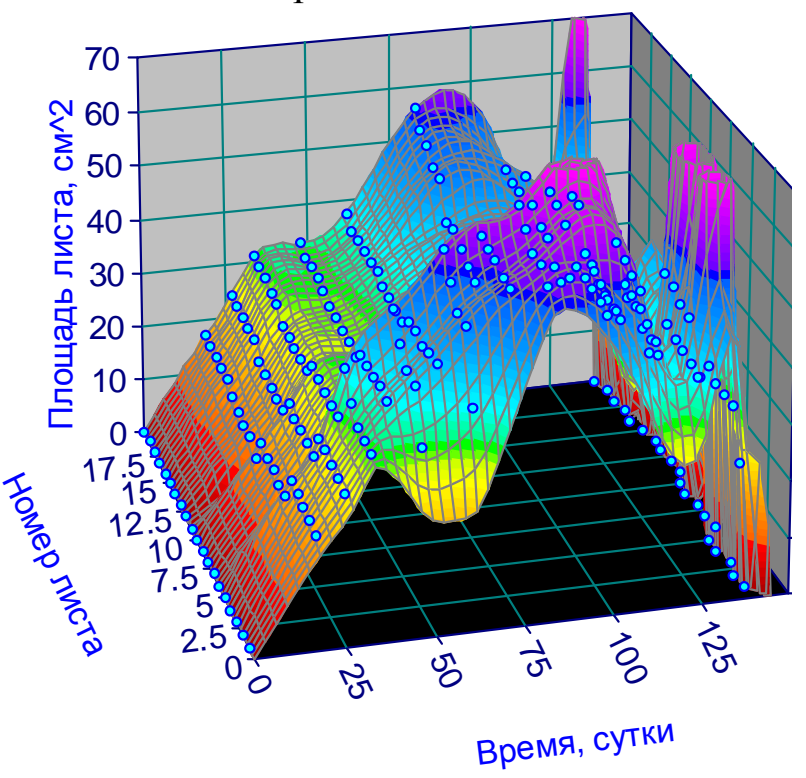

Площадь листа, см²

Рис. 1. Пространственные графики изменения четырех параметров у 20 учетных листьев липы в зависимости от времени цикла вегетационного периода и номера листа

В таблице 1 (фрагмент) за начало вегетационного периода принята дата 02.05.2014, то есть дата начала распускания почек.

В ней даны условные обозначения параметрам листа: 
$a$ - длина листа вдоль главной жилки, измеряемая от места соединения черешка с листовой пластиной растения до конца вершинки листа, мм;

$b$ - ширина листа по крайним точкам поперек листовой пластины или же общая ширина листа в наибольшем поперечном сечении листа, мм;

$P$ - периметр листа, см;

$S$ - площадь листа, измеряемая количеством клеток размерами $2 \times 2$ мм и количеством клеток периметра листа, см² $^{2}$

Таблица 1

Исходные данные (фрагмент) динамики в вегетационный период 2014 года параметров у 20 учетных листьев липы в онтогенезе около автомобильной дороги

\begin{tabular}{|c|c|c|c|c|c|c|c|c|c|c|c|c|c|}
\hline Дата & $\begin{array}{c}\text { Время } \\
t, \text { сут. }\end{array}$ & $\begin{array}{c}\text { № } \\
\text { листа }\end{array}$ & $\begin{array}{c}a, \\
\text { мм }\end{array}$ & $\begin{array}{c}\text { мм } \\
\text { мм }\end{array}$ & $\begin{array}{c}P, \\
\text { см }\end{array}$ & $\begin{array}{c}S, \\
\text { см}^{2}\end{array}$ & Дата & $\begin{array}{c}\text { Время } \\
t, \text { сут. }\end{array}$ & $\begin{array}{c}\text { № } \\
\text { листа }\end{array}$ & $\begin{array}{c}a, \\
\text { мм }\end{array}$ & $\begin{array}{c}b, \\
\text { мм }\end{array}$ & $\begin{array}{c}P, \\
\text { см }\end{array}$ & $\begin{array}{c}S, \\
\text { см}^{2}\end{array}$ \\
\hline Север & & & & & & & Юг & & & & & & \\
\hline 02.05 & 0 & 1 & 0 & 0 & 0 & 0 & 02.05 & 0 & 11 & 0 & 0 & 0 & 0 \\
\hline 21.05 & 19 & 1 & 43.4 & 39 & 19.80 & 18 & 21.05 & 19 & 11 & 37.4 & 33.2 & 14.42 & 11.46 \\
\hline 29.05 & 27 & 1 & 68.6 & 44 & 25.17 & 24.74 & 29.05 & 27 & 11 & 45 & 40.8 & 21.21 & 19.58 \\
\hline 05.06 & 34 & 1 & 93.2 & 69 & 30.83 & 31.26 & 05.06 & 34 & 11 & 70 & 66 & 26.87 & 26.5 \\
\hline 19.06 & 48 & 1 & 102.4 & 87.4 & 33.38 & 31.44 & 19.06 & 48 & 11 & 95 & 84.2 & 35.64 & 27.8 \\
\hline 03.07 & 62 & 1 & 126.2111 .4 & 39.60 & 37.12 & 03.07 & 62 & 11 & 103.4108 .4 & 37.33 & 33.56 \\
\hline 24.07 & 83 & 1 & 138.4133 .2 & 44.69 & 56.48 & 24.07 & 83 & 11 & 124.4122 .8 & 42.71 & 39.38 \\
\hline 21.08 & 111 & 1 & 110.2115 .4 & 42.43 & 43.32 & 21.08 & 111 & 11 & 115.2100 .8 & 39.60 & 38.08 \\
\hline 04.09 & 125 & 1 & 97.4 & 90.8 & 31.40 & 38.02 & 04.09 & 125 & 11 & 94.4 & 80.8 & 25.74 & 31.18 \\
\hline 17.09 & 138 & 1 & 60.8 & 63.2 & 23.76 & 22.08 & 17.09 & 138 & 11 & 62.2 & 104.4 & 20.36 & 22.36 \\
\hline 19.09 & 140 & 1 & 0 & 0 & 0 & 0 & 24.09 & 145 & 11 & 0 & 0 & 0 & 0 \\
\hline 02.05 & 0 & 2 & 0 & 0 & 0 & 0 & 02.05 & 0 & 12 & 0 & 0 & 0 & 0 \\
\hline 21.05 & 19 & 2 & 43.6 & 39.4 & 19.80 & 18.68 & 21.05 & 19 & 12 & 37.6 & 35.4 & 16.40 & 13.56 \\
\hline$\ldots$ & $\ldots$ & $\ldots$ & $\ldots$ & $\ldots$ & $\ldots$ & $\ldots$ & $\ldots$ & $\ldots$ & $\ldots$ & $\ldots$ & $\ldots$ & $\ldots$ & $\ldots$ \\
\hline
\end{tabular}

Периметр и площадь учетного листа вычисляют по формулам:

$$
\begin{gathered}
P=0,1 \sqrt{2^{2}+2^{2}} I_{P}=0,1 \sqrt{8} I_{P}=0,28284 I_{P} ; \\
S=0,04 I_{S}+0,02 I_{P} .
\end{gathered}
$$

Время $t$ становится объясняющей переменной, а параметры учетного листа - зависимыми параметрами (факторами) или показателями. При этом визуально, в начале распускания почек по дате 02.05.2014 у всей группы учетных листьев и в моменты по датам опадения каждого учетного листа, параметры учетных листьев равны нулю (см. табл. 1). Из рисунка 1 видно, что до времени 62 суток после распускания почек все 20 учетные листья изменяют свои параметры примерно одинаково. Поэтому поверхность отклика здесь 
ровная. Через 62 суток после начала онтогенеза заметно влияние внешних параметров (расстояния о автомобильной дороги, высоты расположения над почвой). А после 111 суток онтогенеза каждый лист получает самостоятельный характер роста и развития. Поэтому можно считать доказанным, что загрязненность воздуха автомобильными выхлопами начинает проявляться на жизнедеятельности листьев уже через 62 суток после начала онтогенеза.

\section{Закономерность онтогенеза}

Статистическим моделированием [6] идентифицируются закономерности в виде структур $a=f(t), b=f(t), P=f(t)$ и $S=f(t)$, у которых имеются два нуля - в начале и в конце цикла онтогенеза. Для каждой стороны света были выполнено отдельное статистическое моделирование.

Онтогенез загрязненных листьев березы и липы в загрязненной воздушной среде от начала одновременного распускания почек до опадения листа проходит по биотехнической закономерности вида

$$
y=a_{1} t^{a_{2}} \exp \left(-a_{3} t\right)-a_{4} \exp \left(a_{5} t\right)
$$

где $\quad y$ - показатель, параметр листа (длина, ширина, периметр, площадь),

$t$ - вегетационное время с начала онтогенеза с момента одновременного распускания почек до опадения у всех листьев дерева, сутки,

$a_{1} t^{a_{2}} \exp \left(-a_{3} t\right)$ - биотехнический закон динамики поведения листьев в онтогенезе в период вегетации от распускания почек до опадения листьев,

$-a_{4} \exp \left(a_{5} t\right)$ - негативное влияние (торможение из-за отрицательного знака с ускорением) развитию и росту листьев от влияния загрязненной воздушной среды по закону экспоненциального роста,

$a_{1} \ldots a_{5}$ - параметры модели (3), конкретные значения которых получают в ходе идентификации биотехнической закономерности в программной среде типа CurveExpert по данным измерений параметров учетных листьев.

Закономерность для всех 20 учетных листьев по всем четырем сторонам света показана в таблице 2 и на рисунке 2. 
Параметры модели групा листьев загрязненной липы

\begin{tabular}{|c|c|c|c|c|c|c|c|c|c|}
\hline \multirow{2}{*}{$\begin{array}{l}\text { Азимут } \\
\varphi, \text { град }\end{array}$} & \multicolumn{3}{|c|}{ РасстояниеВысотаВегетац. } & \multicolumn{6}{|c|}{ Параметры статистической модели (3) } \\
\hline & $\begin{array}{c}\text { От дороги } \\
L, \mathrm{M}\end{array}$ & $\begin{array}{l}\text { листа } \\
\bar{H}, \text { см }\end{array}$ & $\begin{array}{c}\text { период } \\
\bar{T}, \text { сут. }\end{array}$ & $a_{1}$ & $a_{2}$ & $a_{3}$ & $a_{4}$ & $a_{5}$ & $r$ \\
\hline \multicolumn{10}{|c|}{ Длина листа, мм } \\
\hline $\mathrm{C}$ & 5,0 & 146 & 139,6 & 0,51552 & 1.66050 & 0,021666 & $1,32229 \mathrm{e}-19$ & 0,34179 & 0,9549 \\
\hline $\mathrm{B}$ & 3,2 & 154 & 143,0 & 0,37322 & 1,76691 & 0,023911 & $2,31183 \mathrm{e}-17$ & 0,29784 & 0,9839 \\
\hline Ю & 3,9 & 159 & 144,4 & 0,22874 & 1,84679 & 0,022789 & $8,26384 \mathrm{e}-10$ & 0,17510 & 0,9832 \\
\hline 3 & 5,8 & 154 & 140,8 & 0,38283 & 1,76296 & 0,023857 & $3,39479 \mathrm{e}-17$ & 0,29938 & 0,9765 \\
\hline 20 шт. & 4,5 & 153 & 142,0 & 0,44933 & 1,68192 & 0,021515 & $2,73458 \mathrm{e}-7$ & 0,13630 & 0,9573 \\
\hline \multicolumn{10}{|c|}{ Ширина листа, мм } \\
\hline $\mathrm{C}$ & 5,0 & 146 & 139,6 & 0,18940 & 1,92406 & 0,024081 & $2,86047 \mathrm{e}-21$ & 0,36877 & 0,9448 \\
\hline $\mathrm{B}$ & 3,2 & 154 & 143,0 & 0,10479 & 2,05697 & 0,024503 & $1,08933 \mathrm{e}-12$ & 0,22336 & 0,9843 \\
\hline Ю & 3,9 & 159 & 144,4 & 0,10375 & 2,05117 & 0,024226 & $4,48564 \mathrm{e}-14$ & 0,24308 & 0,9734 \\
\hline 3 & 5,8 & 154 & 140,8 & 0,087434 & 2,12835 & 0,026079 & $1,92837 \mathrm{e}-19$ & 0,33604 & 0,9639 \\
\hline 20 шт. & 4,5 & 153 & 142,0 & 0,15969 & 1,92933 & 0,022627 & $2,59118 \mathrm{e}-7$ & 0,13686 & 0,9499 \\
\hline \multicolumn{10}{|c|}{ Периметр листа, см } \\
\hline $\mathrm{C}$ & 5,0 & 146 & 139,6 & 1,01147 & 1,09091 & 0,013325 & $8,17102 \mathrm{e}-17$ & 0,28910 & 0,9530 \\
\hline $\mathrm{B}$ & 3,2 & 154 & 143,0 & 0,37532 & 1,41475 & 0,018865 & $6,00308 \mathrm{e}-9$ & 0,15544 & 0,9844 \\
\hline Ю & 3,9 & 159 & 144,4 & 0,25404 & 1,51870 & 0,019573 & 6,83352e-7 & 0,12120 & 0,9849 \\
\hline 3 & 5,8 & 154 & 140,8 & 0,61047 & 1,25514 & 0,016096 & $1,26268 \mathrm{e}-14$ & 0,25079 & 0,9706 \\
\hline 20 шт. & 4,5 & 153 & 142,0 & 0,89977 & 1,09934 & 0,012152 & 0,00023822 & 0,083096 & 0,9637 \\
\hline \multicolumn{10}{|c|}{ Площадь листа, см² } \\
\hline $\mathrm{C}$ & 5,0 & 146 & 139,6 & 0,23255 & 1,57858 & 0,018218 & $2,18465 \mathrm{e}-15$ & 0,26759 & 0,9545 \\
\hline $\mathrm{B}$ & 3,2 & 154 & 143,0 & 0,44743 & 1,28489 & 0,013636 & $1,06970 \mathrm{e}-12$ & 0,21774 & 0,9771 \\
\hline Ю & 3,9 & 159 & 144,4 & 0,38409 & 1,31408 & 0,014345 & $1,79069 \mathrm{e}-8$ & 0,14754 & 0,9860 \\
\hline 3 & 5,8 & 154 & 140,8 & 0,72916 & 1,13720 & 0,010970 & $1,89888 \mathrm{e}-7$ & 0,13603 & 0,9675 \\
\hline 20 шт. & 4,5 & 153 & 142,0 & 0,71427 & 1,13084 & 0,0099777 & 0,00016403 & 0,087477 & 0,9302 \\
\hline
\end{tabular}

По результатам статистического моделирования в таблице 2 приведены параметры моделей с дополнением трех факторов: расстояния от дороги, высоты листа над поверхностью почвы и среднего значения вегетационного периода для 5 учетных листьев и всех 20 учетных листьев липы.

Графики на рисунке 2 показывают, что около дороги стороны света мало влияют на онтогенез учетных листьев (небольшая разница в значениях меры тесноты факторной связи - коэффициенте корреляции). Только периметр и площадь учетного листа при времени вегетации 83 сутки резко отличаются друг друга. Но затем снова с дальнейшим ростом времени вегетации разброс точек снижается. Этот факт указывает на то, что дисперсия является переменной в зависимости от времени вегетации. 

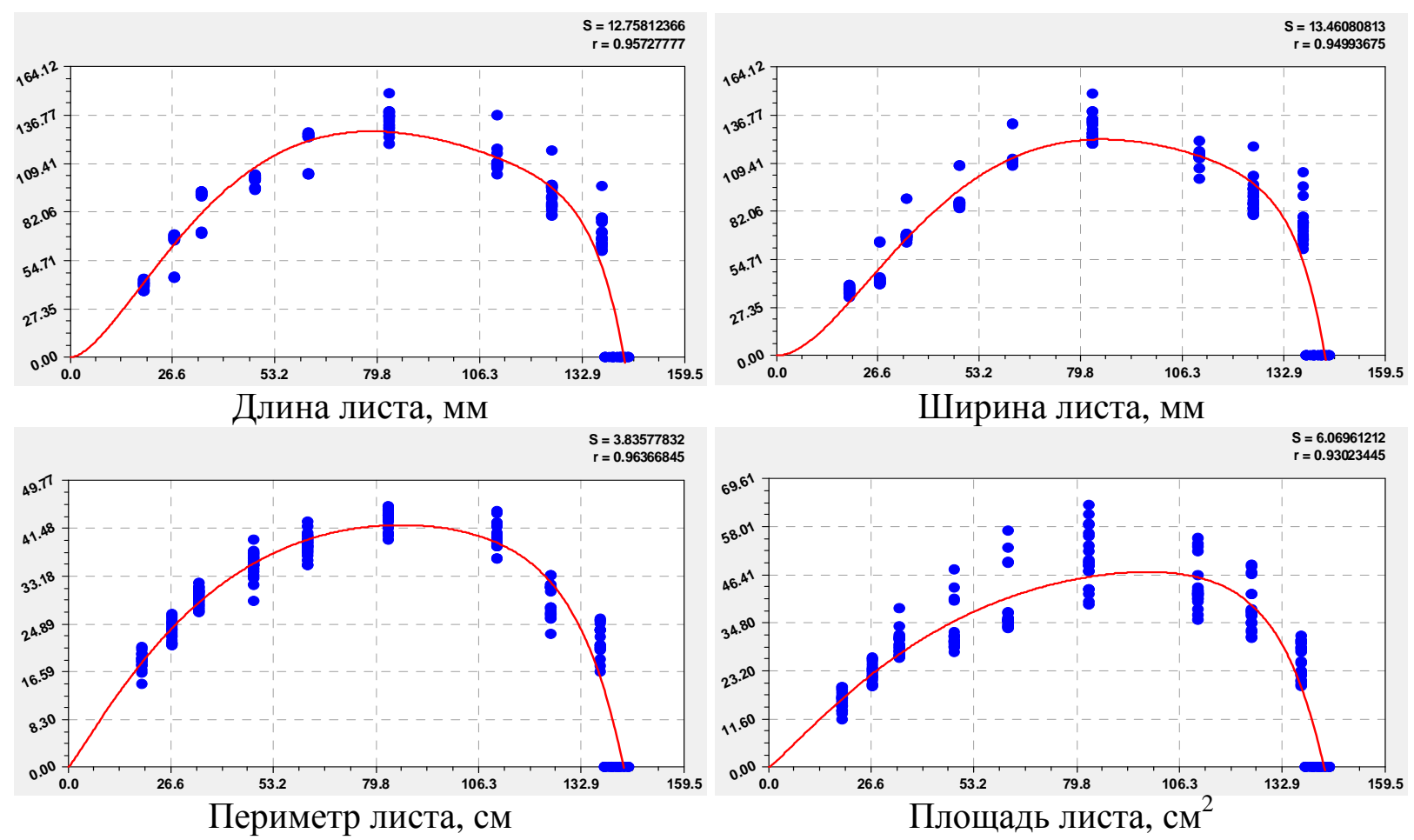

Рис. 2. Графики среднестатистической закономерности по всем 20 листьям липы

Поэтому статистическая выборка динамики онтогенеза является скедастической информацией [7].

\section{Факторный анализ параметров учетных листьев}

В таблице 3 даны максимальные значения у четырех параметров по каждому учетному листу.

Эти максимальные значения для загрязненной липы проявились в один и тот же день 27.08.2014 через 83 сутки от начала вегетации 02.05.2014 по распусканию почек. Однако учетный лист № 10 получил максимум длины через 62 сутки, а остальные три параметра - через 83 сутки. Этот факт указывает на то, что при уточнении методики для повышения точности измерений можно будет определять точнее даты максимума каждого из четырех параметров учетного листа.

У любых факторов имеется четкая векторная ориентация. Например, любой житель села понимает направленность количественных изменений в сельском хозяйстве. Каждый человек стремится к лучшему в своей жизни. Аналогично можно рассматривать любое живое существо, включая и листья. 
Таблица 3

Исходные данные параметров листьев загрязненной березы

\begin{tabular}{|c|c|c|c|c|c|c|c|c|c|}
\hline \multirow{2}{*}{$\begin{array}{c}\text { № } \\
\text { листа }\end{array}$} & \multirow{2}{*}{$\begin{array}{l}\text { Ази- } \\
\text { мут }\end{array}$} & \multirow{2}{*}{\begin{tabular}{|c|} 
Расстояние \\
от дороги \\
$L, \mathrm{M}$ \\
\end{tabular}} & \multirow{2}{*}{$\begin{array}{c}\text { Высота } \\
\text { листа } \\
H, \text { см }\end{array}$} & \multirow{2}{*}{$\begin{array}{c}\text { Вегетац. } \\
\text { период } \\
T, \text { сут. }\end{array}$} & \multicolumn{5}{|c|}{ Максимальные параметры листа } \\
\hline & & & & & $t^{*}$, сут. & $a_{\max }, \mathrm{MM}$ & $b_{\max }, \mathrm{MM}$ & $P_{\max }, \mathrm{cm}$ & $S_{\max }, \mathrm{cm}^{2}$ \\
\hline 1 & \multirow{5}{*}{$\mathrm{C}$} & 5,0 & 146 & 140 & 83 & 138.4 & 133.2 & 44.69 & 56.48 \\
\hline 2 & & 5,0 & 146 & 139 & 83 & 136.4 & 120.4 & 44.12 & 58.48 \\
\hline 3 & & 5,0 & 146 & 141 & 83 & 138.0 & 124.4 & 44.97 & 58.7 \\
\hline 4 & & 5,0 & 146 & 139 & 83 & 131.2 & 131.6 & 45.25 & 60.96 \\
\hline 5 & & 5,0 & 146 & 139 & 83 & 149.2 & 149.2 & 45.25 & 63.28 \\
\hline 6 & \multirow{5}{*}{ B } & 3,2 & 154 & 144 & 83 & 136.4 & 134.8 & 41.58 & 47.26 \\
\hline 7 & & 3,2 & 154 & 143 & 83 & 135.2 & 134.8 & 39.60 & 47.32 \\
\hline 8 & & 3,2 & 154 & 143 & 83 & 136.4 & 124.4 & 43.84 & 48.62 \\
\hline 9 & & 3,2 & 154 & 142 & 83 & 133.2 & 126.4 & 40.45 & 48.62 \\
\hline 10 & & 3,2 & 154 & 143 & $62 / 83$ & 125.0 & 126.8 & 41.86 & 49.44 \\
\hline 11 & \multirow{5}{*}{ Ю } & 3,9 & 159 & 145 & 83 & 124.4 & 122.8 & 42.71 & 39.38 \\
\hline 12 & & 3,9 & 159 & 145 & 83 & 127.2 & 124.8 & 42.99 & 40.04 \\
\hline 13 & & 3,9 & 159 & 144 & 83 & 127.6 & 126.8 & 43.27 & 41.82 \\
\hline 14 & & 3,9 & 159 & 145 & 83 & 130.0 & 128.8 & 43.56 & 43,68 \\
\hline 15 & & 3,9 & 159 & 143 & 83 & 134.4 & 132.8 & 40.16 & 43.04 \\
\hline 16 & \multirow{5}{*}{3} & 5,8 & 154 & 141 & 83 & 136.8 & 121.2 & 40.73 & 49.56 \\
\hline 17 & & 5,8 & 154 & 142 & 83 & 138.8 & 139.2 & 43.84 & 49.94 \\
\hline 18 & & 5,8 & 154 & 141 & 83 & 129.2 & 133.6 & 41.86 & 52.00 \\
\hline 19 & & 5,8 & 154 & 141 & 83 & 139.2 & 120.8 & 43.84 & 53.42 \\
\hline 20 & & 5,8 & 154 & 139 & 83 & 130.8 & 138.8 & 44.69 & 55.72 \\
\hline
\end{tabular}

Поэтому возможны всего два варианта векторов поведения:

а) лучше меньше (по вектору «лучше $\rightarrow$ хуже» к листьям не относится);

б) лучше больше (и это благо для жизнедеятельности листьев).

Как объясняющие переменные учтены еще два фактора: расстояние от дороги и высота от поверхности почвы до группы учетных листьев.

Все бинарные отношения между факторами идентифицируются общей биотехнической закономерностью в виде формулы тренда

$$
\begin{gathered}
y_{m}=y_{m 1}+y_{m 2}, \\
y_{m 1}=a_{1} x^{a_{2}} \exp \left(-a_{3} x^{a_{4}}\right), y_{m 2}=a_{5} x^{a_{6}} \exp \left(-a_{7} x^{a_{8}}\right),
\end{gathered}
$$

где $y_{m}$ - тренд, $x$ - объясняющая переменная, $a_{1} \ldots a_{8}$ - параметры тренда (4). При этом каждый параметр модели (4) имеет физический смысл.

Физико-математический подход предполагает понимание смысла динамического ряда по вегетационному периоду как отражения какого-то со- 
ставного процесса или же множества последовательно и параллельно происходящих природных и/или природно-антропогенных процессов.

Тогда любое уравнение биотехнической закономерности с волновыми составляющими (появляются из-за волновой адаптации деревьев и их листьев к окружающей среде, в нашем случае к воздушной среде) можем записать как вейвлет-сигнал [6] вида

$$
\begin{array}{r}
y_{i}=A_{i} \cos \left(\pi x / p_{i}-a_{8 i}\right), \\
A_{i}=a_{1 i} x^{a_{2 i}} \exp \left(-a_{3 i} x^{a_{4 i}}\right), p_{i}=a_{5 i}+a_{6 i} x^{a_{7 i}},
\end{array}
$$

где $A_{i}$ - амплитуда (половина) вейвлета (ось $y$ ), $p_{i}$ - полупериод волны (ось $x), a_{1 i} \ldots a_{8 i}$ - параметры модели (5), получаемые в CurveExpert по статистическим данным, $i$ - номер составляющей модели (5).

Рейтинг факторов по коэффициентам корреляции. В таблице 7 приведены коэффициенты корреляции закономерностей у всех ранговых (рис. 3) и бинарных распределений по тренду (4).

Таблица 4

\begin{tabular}{|c|c|c|c|c|c|c|c|}
\hline \multirow{2}{*}{$\begin{array}{c}\text { Факторы } \\
\text { как объясняющие } \\
\text { переменные } x\end{array}$} & \multicolumn{5}{|c|}{ Факторы - показатели $y$} & \multirow{2}{*}{$\begin{array}{l}\text { Сумма } \\
\text { коэфф. } \\
\text { коррел. }\end{array}$} & \multirow{2}{*}{$\begin{array}{c}\text { Рей- } \\
\text { тинг } \\
I_{x}\end{array}$} \\
\hline & $\begin{array}{c}T, \\
\text { сут. }\end{array}$ & $\begin{array}{c}a_{\max } \\
\mathrm{MM}\end{array}$ & $\begin{array}{c}b_{\max } \\
\text { MM }\end{array}$ & $\begin{array}{c}P_{\max } \\
\mathrm{cM}\end{array}$ & $\begin{array}{c}S_{\max }, \\
\mathrm{cm}^{2}\end{array}$ & & \\
\hline Расст. от дороги $L$, м & 0,9170 & 0,6202 & 0,2359 & 0,7108 & 0,9626 & 3,4465 & 3 \\
\hline Высота листа $H$, см & 0,8337 & 0,5958 & 0,2135 & 0,6382 & 0,9258 & 3,2070 & 5 \\
\hline Вегет. период $T$, сут. & 0,9962 & 0,5330 & 0,3205 & 0,6647 & 0,9269 & 3,4413 & 4 \\
\hline Длина листа $a_{\text {max }}$, мм & 0,5704 & 0,9656 & 0,4330 & 0,3556 & 0,6192 & 2,9438 & 7 \\
\hline Ширина листа $b_{\text {max }}$, мм & 0,4617 & 0,6932 & 0,9888 & 0,3601 & 0,4591 & 2,9629 & 6 \\
\hline Периметр $P_{\max }, \mathrm{cm}$ & 0,7272 & 0,5739 & 0,5109 & 0,9924 & 0,8261 & 3,6305 & 1 \\
\hline Площадь $S_{\max }, \mathrm{cm}^{2}$ & 0,9279 & 0,6209 & 0,3257 & 0,7605 & 0,9918 & 3,6268 & 2 \\
\hline Сумма коэфф. коррел. & 5,4341 & 4,6026 & 3,0283 & 4,4823 & 5,7115 & 23,2588 & - \\
\hline Рейтинг $I_{y}$ & 2 & 3 & 5 & 4 & 1 & - & 0,6645 \\
\hline
\end{tabular}

Корреляционная матрица и рейтинг факторов по детерминированным моделям

Коэффициент коррелятивной вариации множества факторов физического объекта исследования равен отношению общей суммы коэффициентов корреляции к произведению количества факторов по строкам и столбцам. В нашем примере по данным таблицы 4 коэффициент коррелятивной вариации 
соответственно будет равен $23,2588 /(7 \times 5)=0,6645$. Это достаточно высокий показатель функциональной связности отдельных элементов системы «листья - почва - дорога» при детерминированных закономерностях.

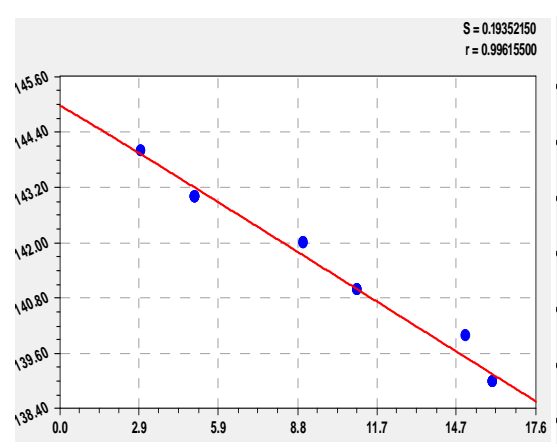

Период вегетации, сутки

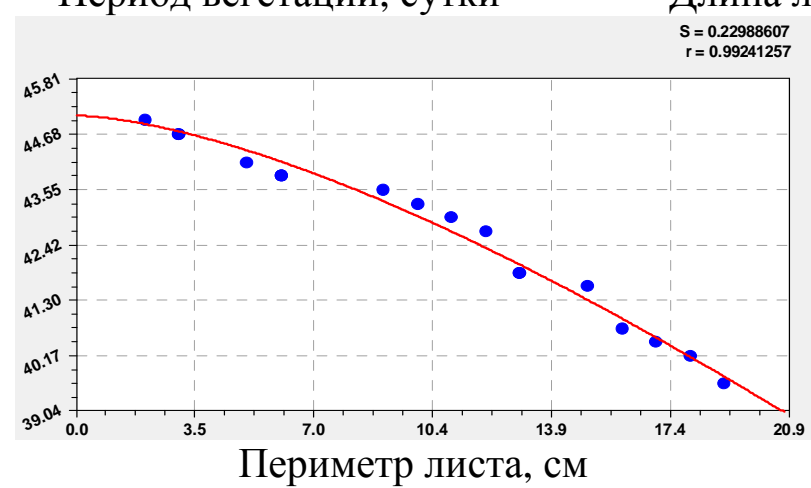

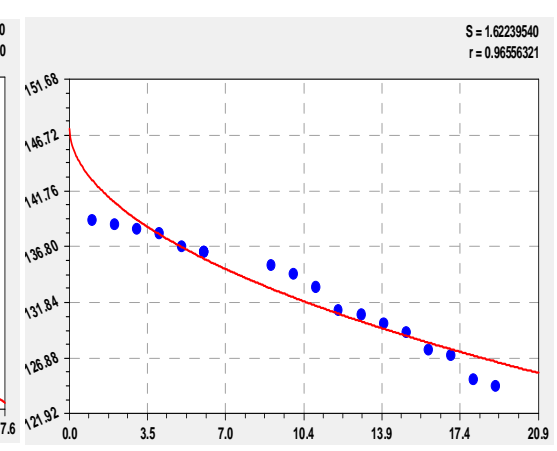

Длина листа, мм

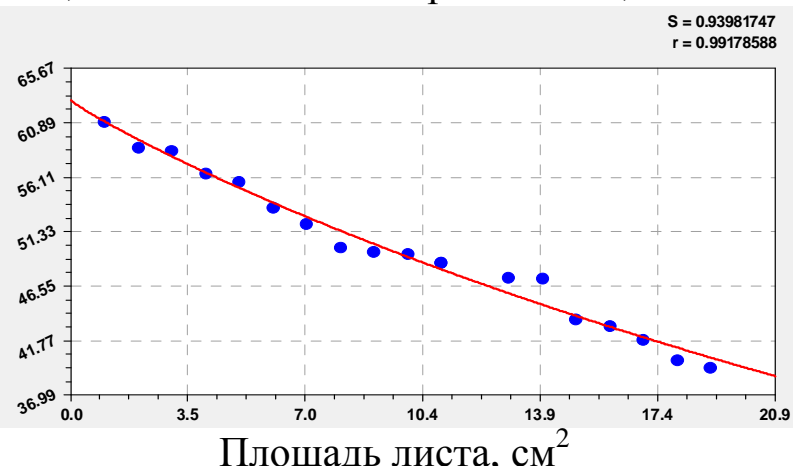

Рис. 3. Графики ранговых распределений вегетационного периода и четырех параметров формы листьев липы

Этот критерий применяется при сравнении различных объектов исследования, в данном случае листвы деревьев в различных экологических условиях произрастания. При этом вид изучаемой системы не влияет на указанный критерий верификации, а коррелятивная вариация полностью зависит от внутренних свойств системы.

По рейтингу среди влияющих переменных на первом месте оказался периметр, на втором - площадь учетного листа и на третьем - расстояние от дороги. При этом рейтинг биологических параметров листьев оказался выше по сравнению с параметром места произрастания. А биологический фактор длины учетного листа оказался на седьмом последнем месте.

Как показатель на первом месте находится площадь учетного листа, на втором - вегетационный период и на третьем месте - длина листа. 


\section{Корреляционная матрица бинаров}

Рассмотрим без строк и столбцов показателей рейтинга из таблицы 4 (табл. 5) коэффициенты корреляции бинарных отношений. Поэтому диагональные клетки с адекватностью ранговых распределений исключаем.

Таблица 5

Корреляционная матрица по детерминированным моделям бинаров

\begin{tabular}{|c|c|c|c|c|c|}
\hline \multirow{2}{*}{$\begin{array}{c}\text { Факторы } \\
\text { как объясняющие } \\
\text { переменные } x\end{array}$} & \multicolumn{5}{|c|}{ Факторы - показатели $y$} \\
\hline & $\begin{array}{c}T, \\
\text { сут. }\end{array}$ & $\begin{array}{c}a_{\max } \\
\text { MM }\end{array}$ & $\begin{array}{c}b_{\max } \\
\text { MM }\end{array}$ & $\begin{array}{c}P_{\max } \\
\mathrm{cM}\end{array}$ & $\begin{array}{l}S_{\max }, \\
\mathrm{CM}^{2}\end{array}$ \\
\hline Расстояние от дороги $L$, м & 0,9170 & 0,6202 & 0,2359 & 0,7108 & 0,9626 \\
\hline Высота листа $H$, см & 0,8337 & 0,5958 & 0,2135 & 0,6382 & 0,9258 \\
\hline Вегет. период $T$, сут. & & 0,5330 & 0,3205 & 0,6647 & 0,9269 \\
\hline Длина листа $a_{\max }$, мм & 0,5704 & & 0,4330 & 0,3556 & 0,6192 \\
\hline Ширина листа $b_{\max }$, мм & 0,4617 & 0,6932 & & 0,3601 & 0,4591 \\
\hline Периметр $P_{\max }$, см & 0,7272 & 0,5739 & 0,5109 & & 0,8261 \\
\hline Площадь $S_{\max }$, см$^{2}$ & 0,9279 & 0,6209 & 0,3257 & 0,7605 & \\
\hline
\end{tabular}

Остаются только бинарные отношения 30 штук. Чаще всего выделяют сильные закономерности с коэффициентом корреляции $r \geq 0,7$.

В таблице 6 дан рейтинг отношений с волновыми составляющими.

Таблица 6

Корреляционная матрица и рейтинг факторов по моделям с волновыми членами

\begin{tabular}{|l|c|c|c|c|c|c|c|}
\hline \multirow{2}{*}{$\begin{array}{c}\text { Факторы } \\
\text { как объясняющие } \\
\text { переменные } x\end{array}$} & $\begin{array}{c}T, \\
\text { сут. }\end{array}$ & $\begin{array}{c}a_{\max }, \\
\text { мм }\end{array}$ & $\begin{array}{c}b_{\max }, \\
\text { мм }\end{array}$ & $\begin{array}{c}P_{\max }, \\
\text { см }\end{array}$ & $\begin{array}{c}S_{\max }, \\
\text { см }^{2}\end{array}$ & $\begin{array}{c}\text { Сумма } \\
\text { коэфф. } \\
\text { Коррел. }\end{array}$ & $\begin{array}{c}\text { Рей- } \\
\text { тинг } \\
I_{x}\end{array}$ \\
\hline Расст. от дороги $L$, м & 0,9170 & 0,6202 & 0,2359 & 0,7108 & 0,9626 & 3,4465 & 4 \\
\hline Высота листа $H$, см & 0,8337 & 0,5958 & 0,2135 & 0,6382 & 0,9258 & 3,2070 & 7 \\
\hline Вегет. период $T$, сут. & 0,9962 & 0,5330 & 0,3205 & 0,6647 & 0,9269 & 3,4413 & 5 \\
\hline Длина листа $a_{\max }$, мм & $\mathbf{0 , 7 1 0 9}$ & 0,9656 & $\mathbf{0 , 7 0 6 7}$ & $\mathbf{0 , 7 7 2 7}$ & $\mathbf{0 , 7 5 9 4}$ & 3,9153 & 3 \\
\hline Ширина листа $b_{\max }$, мм & 0,4616 & $\mathbf{0 , 8 0 6 6}$ & 0,9888 & $\mathbf{0 , 6 3 2 9}$ & 0,4591 & 3,3490 & 6 \\
\hline Периметр $P_{\max }$, см & $\mathbf{0 , 9 2 1 0}$ & $\mathbf{0 , 7 7 1 7}$ & $\mathbf{0 , 5 4 3 0}$ & 0,9924 & $\mathbf{0 , 9 6 3 7}$ & 4,1918 & 2 \\
\hline Площадь $S_{\max }$, см & 0,9279 & 0,6209 & $\mathbf{0 , 8 7 0 2}$ & $\mathbf{0 , 8 6 2 7}$ & 0,9918 & 4,2735 & 1 \\
\hline Сумма коэфф. коррел. & 5,7683 & 4,9138 & 3,8786 & 5,2744 & 5,9893 & 25,8244 & - \\
\hline Рейтинг $I_{y}$ & 2 & 4 & 5 & 3 & 1 & - & 0,7378 \\
\hline
\end{tabular}

Примечание. Полужирным шрифтом выделены связи с волновыми составляющими.

Коэффициент коррелятивной вариации стал равен 25,8244 / $35=0,7378$.

По рейтингу среди влияющих переменных на первом месте оказалась площадь, на втором - периметр и на третьем - длина. А фактор высоты учет- 
ного листа оказался на последнем седьмом месте. Как показатель на первом месте находится снова площадь, на втором - вегетационный период и на третьем месте - периметр вместо длины по детерминированным моделям.

Сильные бинары. Влияние расстояния и высоты не изменилось (рис. 4 и рис. 5) при трендах (табл. 4) и волновых возмущений (табл. 6).

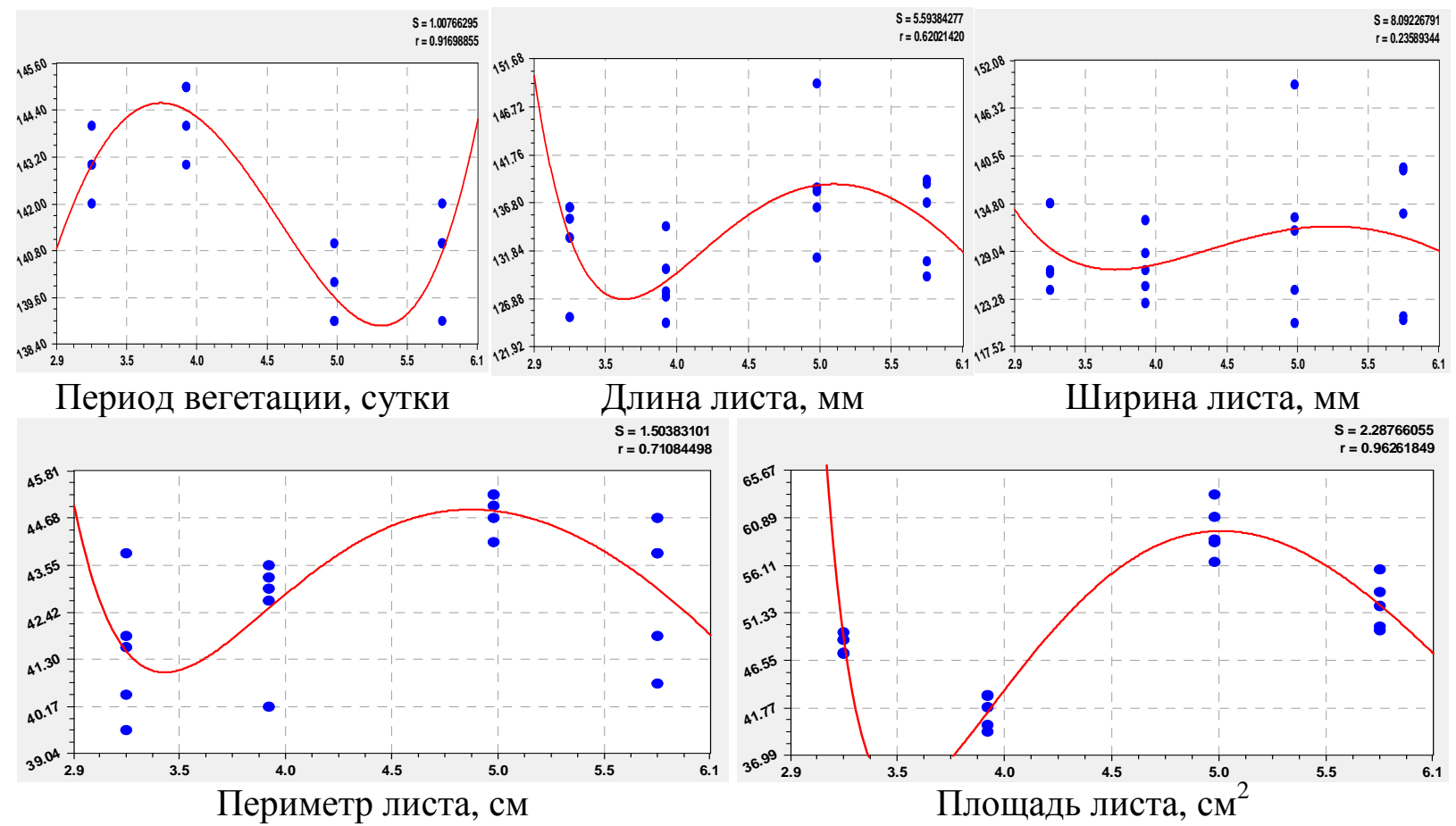

Рис. 4. Графики влияния расстояния от дороги

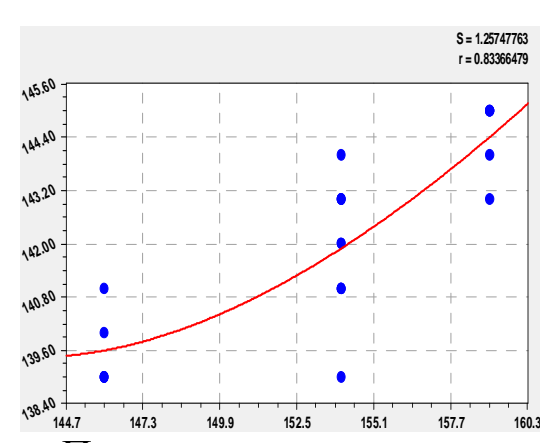

Период вегетации, сутки

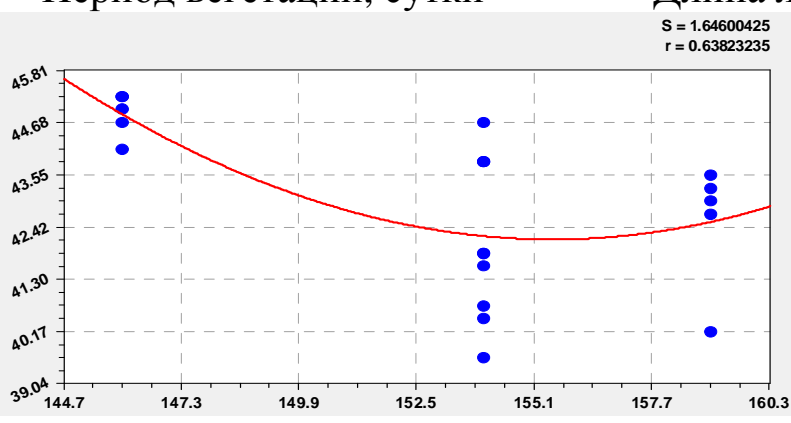

Периметр листа, см

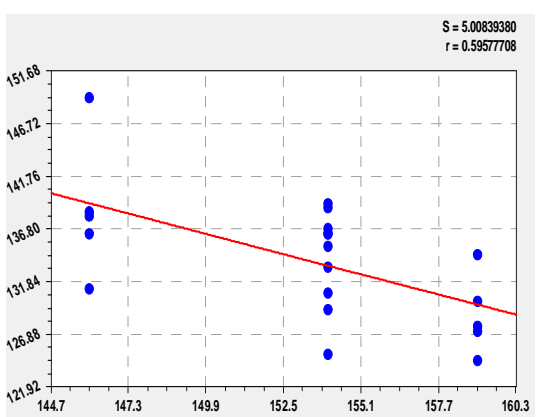

Длина листа, мм

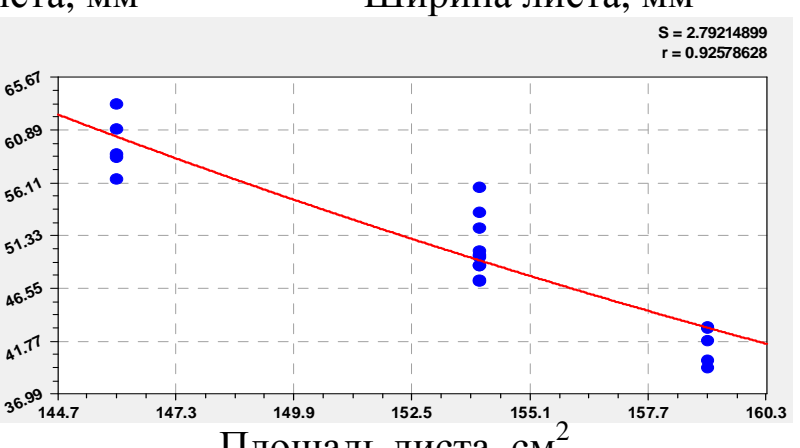

Площадь листа, см ${ }^{2}$

Рис. 5. Графики влияния высоты расположения учетных листьев 
Закономерности с допустимым уровнем адекватности по коэффициенту корреляции $r \geq 0,7$ даны в таблице 7 .

Таблица 7

\begin{tabular}{|c|c|c|c|c|c|}
\hline \multicolumn{6}{|c|}{ орреляционная матрица по трендам и волновым моделям сильных бина] } \\
\hline \multirow{2}{*}{$\begin{array}{c}\text { Факторы } \\
\text { как объясняющие } \\
\text { переменные } x\end{array}$} & \multicolumn{5}{|c|}{ Факторы - показатели $y$} \\
\hline & $\begin{array}{c}T, \\
\text { сут. }\end{array}$ & $\begin{array}{c}a_{\text {max }}, \\
\text { MM }\end{array}$ & $\begin{array}{c}b_{\max } \\
\text { MM }\end{array}$ & $\begin{array}{c}P_{\max } \\
\mathrm{cM}\end{array}$ & $\begin{array}{l}S_{\max }, \\
\mathrm{CM}^{2}\end{array}$ \\
\hline Расстояние от дороги $L, \mathrm{M}$ & 0,9170 & & & 0,7108 & 0,9626 \\
\hline Высота листа $H$, см & 0,8337 & & & & 0,9258 \\
\hline Вегет. период $T$, сут. & & & & & 0,9269 \\
\hline Длина листа $a_{\max }$, мм & 0,7109 & & 0,7067 & 0,7727 & 0,7594 \\
\hline Ширина листа $b_{\max }$, мм & & 0,8066 & & & \\
\hline Периметр $P_{\max }$, см & $\mathbf{0 , 9 2 1 0}$ & 0,7717 & & & 0,9637 \\
\hline Площадь $S_{\max }, \mathrm{cm}^{2}$ & 0,9279 & & $\mathbf{0 , 8 7 0 2}$ & 0,8627 & \\
\hline
\end{tabular}

Для моделей с волнами получились 17 (больше на 70\%) формул вместо 10 по детерминированным уравнениям. Все столбцы и строки сохранились. Далее ужесточим требования к адекватности до уровня 0,9 (табл. 8).

Таблица 8

Корреляционная матрица при $r \geq 0,9$

\begin{tabular}{|l|c|c|}
\hline \multirow{2}{*}{$\begin{array}{c}\text { Факторы } \\
\text { как объясняющие } \\
\text { переменные } x\end{array}$} & \multicolumn{2}{|c|}{ Показатели $y$} \\
\cline { 2 - 3 } & $\begin{array}{c}T, \\
\text { сут. }\end{array}$ & $\begin{array}{c}S_{\max }, \\
\text { см }^{2}\end{array}$ \\
\hline Расстояние от дороги $L, \mathrm{M}$ & 0,9170 & 0,9626 \\
\hline Высота листа $H$, см & & 0,9258 \\
\hline Вегет. период $T$, сут. & & 0,9269 \\
\hline Периметр $P_{\max }$, см & $\mathbf{0 , 9 2 1 0}$ & $\mathbf{0 , 9 6 3 7}$ \\
\hline Площадь $S_{\max }, \mathrm{cm}^{2}$ & 0,9279 & \\
\hline
\end{tabular}

Осталось всего семь сильнейших факторных связей. Из бинарных отношений, как влияющие переменные и как показатели, исключились линейные параметры (длина листа $a_{\max }$, мм; ширина листа $b_{\max }$, мм) и остался периметр $P_{\max }$ учетного листа липы, см. однако периметр получил высокую адекватность только с учетом волновых составляющих.

При этом на месте около дороги с сильным загрязнением воздуха наибольшее влияние оказывает расстояние от дороги до группы листьев липы (корреляция максимальна и равна 0,9626). Как показатели остаются вегетационный период (легко измерить по фенологическим наблюдениям) и площадь учетных листьев липы.

По убыванию адекватности получили следующие закономерности: 
- зависимость $S_{\max }=f\left(P_{\max }\right)$ при $r=0,9637$

$S_{\max }=5,51512 \cdot 10^{-6} \exp \left(2,95256 P_{\max }^{0,50635}\right)-4,62456 \cdot 10^{-14} P_{\max }^{10,21104}+$

$$
+A \cos \left(\pi P_{\max } / p+1,64232\right)
$$

$A=7,94899 \cdot 10^{-79} P_{\max }{ }^{64,67468} \exp \left(-1,43484 P_{\max }\right)$,

$p=34,04388-0,63647 P_{\max }$;

- зависимость $S_{\max }=f(L)$ при $r=0,9626$

$$
\begin{gathered}
S_{\max }=1,24298 \cdot 10^{10} \exp (-6,21652 L)+ \\
+0,027106 L^{12,51131} \exp (-2,48817 L) ;
\end{gathered}
$$

- закономерность $T=f\left(S_{\max }\right)$ при $r=0,9279$

$$
T=174,42032 \exp \left(-0,031522 S_{\max }^{0,47957}\right) ;
$$

- формула $S_{\max }=f(T)$ при корреляции $r=0,9269$

$$
\begin{gathered}
S_{\max }=1392,3087 \exp \left(7,52482 \cdot 10^{-5} T\right)- \\
-8,16555 T^{1,20845} \exp (-0,0061664 T) ;
\end{gathered}
$$

- формула $S_{\max }=f(H)$ при корреляции $r=0,9258$

$$
S_{\max }=592,92752 \exp \left(-0,00072485 H^{1,61656}\right) ;
$$

- закономерность $T=f\left(P_{\max }\right)$ при $r=0,9210$

$$
\begin{aligned}
& T=139,38949 \exp \left(2,38942 \cdot 10^{-5} P_{\max }^{2,01572}\right)-2,31963 \cdot 10^{-32} P_{\max }^{1,96715}+ \\
& +A \cos \left(\pi P_{\max } / p+4,11543\right), \\
& A=1,62346 \cdot 10^{-13} P_{\max }{ }^{11,33240} \exp \left(-0,38726 P_{\max }{ }^{0,91962}\right) \text {, } \\
& p=131,57858-0,84049 P_{\max }^{1,30723} \text {; } \\
& \text { - закономерность } T=f(L) \text { при } r=0,9170 \\
& \begin{array}{c}
T=71,81972 \exp (0,32988 L)- \\
-1,51293 L^{3,82001} \exp (-0,22124 L) .
\end{array}
\end{aligned}
$$

В таблице 9 даны параметры всех 17 моделей, имеющих сильные факторные связи при коэффициенте корреляции, большем 0,7 . 
Таблица 9

Параметры вейвлет-сигналов поведения учетных листьев загрязненной липы

\begin{tabular}{|c|c|c|c|c|c|c|c|c|c|}
\hline \multirow{2}{*}{$\begin{array}{c}x \rightarrow \\
y\end{array}$} & \multicolumn{4}{|c|}{ Амплитуда колебания (5) } & \multicolumn{4}{|c|}{ Полупериод и сдвиг колебания (5) } & \multirow{2}{*}{$\begin{array}{l}\text { Коэф. } \\
\text { корр. }\end{array}$} \\
\hline & $a_{1 i}$ & $a_{2 i}$ & $a_{3 i}$ & $a_{4 i}$ & $a_{5 i}$ & $a_{6 i}$ & $a_{7 i}$ & $a_{8 i}$ & \\
\hline \multirow{3}{*}{$\begin{array}{l}P_{\max } \\
S_{\max }\end{array}$} & $5,51512 \mathrm{e}-6$ & 0 & $-2,95256$ & 0,50635 & 0 & 0 & 0 & 0 & \multirow{3}{*}{0,9637} \\
\hline & $-4,62246 \mathrm{e}-14$ & 10,21104 & 0 & 0 & 0 & 0 & 0 & 0 & \\
\hline & $7,94899 \mathrm{e}-79$ & 64,67468 & 1,43484 & 1 & 34,04388 & $-0,63647$ & 1 & $-1,64322$ & \\
\hline \multirow{2}{*}{$\begin{array}{c}L- \\
S_{\max }\end{array}$} & $1,24298 \mathrm{e} 10$ & 0 & 6,21652 & 1 & 0 & 0 & 0 & 0 & \multirow{2}{*}{0,9626} \\
\hline & 0,027106 & 12,51131 & 2,48817 & 1 & 0 & 0 & 0 & 0 & \\
\hline$S_{\max }-T$ & 174,42032 & 0 & 0,031522 & 0,47957 & 0 & 0 & 0 & 0 & 0,9279 \\
\hline \multirow{2}{*}{$\begin{array}{c}T- \\
S_{\max }\end{array}$} & 1392,3087 & 0 & $-7,52482 e-5$ & 1 & 0 & 0 & 0 & 0 & \multirow{2}{*}{0,9269} \\
\hline & $-8,16555$ & 1,20845 & 0,0061664 & 1 & 0 & 0 & 0 & 0 & \\
\hline$H-S_{\text {max }}$ & 592,92752 & 0 & 0,00072485 & 1,61656 & 0 & 0 & 0 & 0 & 0,9258 \\
\hline \multirow{3}{*}{$\begin{array}{c}P_{\max }- \\
T\end{array}$} & 139,38949 & 0 & $-2,38942 e-5$ & 2,01572 & 0 & 0 & 0 & 0 & \multirow{3}{*}{0,9210} \\
\hline & $-2,31963 e-32$ & 1,96715 & 0 & 0 & 0 & 0 & 0 & 0 & \\
\hline & $1,62346 \mathrm{e}-13$ & 11,33240 & 0,38726 & 0,91962 & 131,57858 & $-0,84049$ & 1,30723 & $-4,11543$ & \\
\hline \multirow{2}{*}{$L-T$} & 71,81972 & 0 & $-0,32988$ & 1 & 0 & 0 & 0 & 0 & \multirow{2}{*}{0,9170} \\
\hline & $-1,51293$ & 3,82001 & 0,22124 & 1 & 0 & 0 & 0 & 0 & \\
\hline \multirow{2}{*}{$\begin{array}{c}S_{\max }- \\
b_{\max }\end{array}$} & 98,86578 & 0,069513 & 0 & 0 & 0 & 0 & 0 & 0 & \multirow{2}{*}{0,8702} \\
\hline & $6,07309 \mathrm{e}-14$ & 8,20524 & 0 & 0 & 2,80502 & $-0,00083242$ & 1,45324 & 0,26673 & \\
\hline \multirow{3}{*}{$\begin{array}{c}S_{\max }- \\
P_{\max }\end{array}$} & 91,05698 & 0 & 0,00038198 & 2,28006 & 0 & 0 & 0 & \begin{tabular}{|l|}
0 \\
\end{tabular} & \multirow{3}{*}{0,8627} \\
\hline & 0,00019536 & 3,38167 & 0,00053557 & 1,94276 & 0 & 0 & \begin{tabular}{|l|}
0 \\
\end{tabular} & \begin{tabular}{|l|}
0 \\
\end{tabular} & \\
\hline & $1,45338 \mathrm{e}-33$ & 28,36216 & 0,69053 & 1,00703 & 0,98694 & 0,00042047 & 1,15145 & 3,41715 & \\
\hline \multirow{2}{*}{$H-T$} & 34498,2307 & 0 & 0,052388 & \begin{tabular}{|l|}
1 \\
\end{tabular} & 0 & 0 & \begin{tabular}{|l|}
0 \\
\end{tabular} & 0 & \multirow{2}{*}{0,8337} \\
\hline & 0,36199 & 1,16975 & 0 & 0 & 0 & 0 & 0 & 0 & \\
\hline \multirow{4}{*}{$\begin{array}{l}b_{\text {max }}- \\
a_{\text {max }}\end{array}$} & 57573,9173 & 0 & $-0,21890$ & 0,18203 & 0 & 0 & 0 & 0 & \multirow{4}{*}{0,8066} \\
\hline & $-61136,8273$ & 0,096467 & 0 & 0 & 0 & 0 & 0 & 0 & \\
\hline & 22,83972 & 4,56758 & 0,16020 & 1,03817 & 2,11511 & $-0,0023324$ & 1,35402 & $*$ & \\
\hline & - & - & - & - & - & 0,0040502 & 1,21281 & 0,96106 & \\
\hline \multirow{3}{*}{$\begin{array}{c}a_{\max }- \\
P_{\max }\end{array}$} & 25678,6538 & 0 & 0,060142 & 1 & 0 & 0 & 0 & 0 & \\
\hline & 0,0019586 & 1,99355 & 0 & 0 & 0 & 0 & \begin{tabular}{|l|}
0 \\
\end{tabular} & 0 & 0,7727 \\
\hline & $4,73813 \mathrm{e}-37$ & 20,10346 & 0,022729 & 1,31448 & 7,0493 & $-0,014295$ & 0,96046 & 4,96089 & \\
\hline & 12540,2917 & 0 & 0,081767 & 1,10923 & 0 & 0 & 0 & 0 & \\
\hline & $2,34358 \mathrm{e}-10$ & 7,01372 & 0 & 0 & 0 & 0 & 0 & 0 & 0,7717 \\
\hline$a_{\max }$ & $3,99180 \mathrm{e}-100$ & 70,98848 & 0,013522 & 2,10057 & 20,87906 & $-0,010680$ & 1,91121 & $-2,59125$ & \\
\hline & 0,0074608 & 1,79965 & 0 & \begin{tabular}{|l|}
0 \\
\end{tabular} & 0 & 0 & \begin{tabular}{l|}
0 \\
\end{tabular} & \begin{tabular}{|l|}
0 \\
\end{tabular} & \\
\hline & $-3,33864 e-93$ & 51,30109 & 0,013630 & 1,61378 & 5,09560 & $-0,0053941$ & 1,03692 & $*$ & 0,7594 \\
\hline$S_{\max }$ & - & - & - & - & - & 0,00036102 & 1,34600 & $-4,80081$ & \\
\hline & 82216,1989 & 0 & 0,030167 & 1 & 0 & 0 & 0 & 0 & \\
\hline$a_{\max }$ & $-27,32529$ & 2,13936 & 0,049364 & 1 & 0 & 0 & 0 & 0 & 0,7109 \\
\hline$T$ & $1,32290 \mathrm{e}-43$ & 25,90744 & 0,12479 & 1,10536 & 6,25661 & $-0,0014295$ & 1,39476 & $-1,91104$ & \\
\hline$L-$ & 68245,7916 & \begin{tabular}{|l|}
0 \\
\end{tabular} & 2,92751 & 1,00022 & $\begin{array}{l}0 \\
\end{array}$ & 0 & 0 & 0 & \\
\hline$P_{\max }$ & 8,19074 & 2,87651 & 0,58594 & 1,00002 & 0 & 0 & 0 & 0 & \\
\hline$a_{\max }-$ & 82,85293 & 0 & $-0,00014262$ & 1,65066 & 0 & 0 & 0 & 0 & \\
\hline$b_{\max }$ & $1,15512 \mathrm{e}-25$ & 12,05829 & 0 & 0 & 0,38395 & 0,009779 & 1,00030 & $-4,86104$ & \\
\hline
\end{tabular}

Формула (5) с полупериодом колебания $p_{i}=a_{5 i}+a_{6 i} x^{a_{7 i}} \exp \left(-a_{9} x^{a_{10}}\right)$. 
По формуле (7) можно определить рациональное расстояние от края дороги, когда будет максимальная площадь учтенного листа липы. По графику на рисунке 4 получаем, что максимальная площадь листьев липы наблюдается на 5 м от края бордюра дороги. При меньшем и большем расстояниях площадь листьев уменьшается. Это происходит из-за волнового распределения концентрации загрязнения воздуха, когда максимум концентрации от выхлопных газов автомобилей наблюдается дальше от края дороги.

Выводы. Преимуществом предлагаемого способа является техническая простота исполнения, так как из оборудования требуется только изготовить даже самому прозрачную палетку, например из листового оргстекла, а сотовый телефон с функцией фотографирования ныне очень распространен и имеется почти у каждого студента или школьника. Для измерений расстояний принимается рулетка, а для измерения высоты учтенных листьев над поверхностью почвы берется метровая миллиметровая линейка.

Кроме того, преимуществом является идентификация динамических рядов измерений среднестатистической динамики роста не менее пяти учетных листьев липы по каждой стороне света и 20 учетных листьев по всему дереву березы. При этом онтогенез листьев липы в загрязненной воздушной среде характеризуется трендом, содержащим всего две составляющие: первая показывает динамику развития и роста листьев по биотехническому закону, а вторая - негативное воздействие на онтогенез учетных листьев загрязнения воздуха по закону экспоненциального роста со временем вегетации листьев.

Способ может быть широко реализован в школьных экологических кружках, пришкольных лесничествах, и даже в детских садах, а также в любых географических и иных экспедициях. Кроме измерений параметров у групп по сторонам света из не менее пяти учетных листьев в таблицу измеренных данных по датам визуально ставятся нули в начале (день распускания почек у всех листьев дерева) и в конце (день опадения каждого учетного листа в отдельности) вегетационного периода онтогенеза. Для использования 
предлагаемого способа нужно изготовить прозрачную палетку с сеткой клетками размером $2 \times 2$ мм, иметь сотовый телефон с функциями фотографирования, хранения фотографий в памяти и передачи их в персональный компьютер. В компьютере должна быть программная среда типа CurveExpert для выявления устойчивых закономерностей.

\section{Литература}

1. Кудряшова А.И. Описательная статистика параметров формы листьев липы // Проблемы рекреационных насаждений, интродукции и сохранения биоразнообразия растительного мира: Матер. Российской научно-практ. конф. с междунар. участием, посвящ. 25-летию организации Чебоксарского ф-ла Главного ботанич. сада им. Н.В. Цицина РАН. Чебоксары, 2014. С. 27-30.

2. Кудряшова А.И. Анализ онтогенеза листьев липы // Материалы научно-практической конференции «Математическое моделирование в области клеточной биологии, биохимии и биофизики» 25-26 ноября 2014 г. Тольятти: Тольяттинский ГУ, 2014. С. 137-145.

3. Кудряшова А.И. Способ измерения периметра и площади листа дерева // III Международной научно-практической конференции «Актуальные вопросы науки и хозяйства: новые вызовы и решения». СПб.: Общественная научная организация «Наука и хозяйство». № 3. 2014. С. 17-20.

4. Кудряшова А.И. Способ измерения периметра и площади листа у древесных растений // «Опыт прошлого - взгляд в будущее» - 4-я Международная научно-практическая конференция молодых ученых и студентов. Материалы конференции. Тула: ТулГУ, 2014, С. 372-376.

5. Кудряшова А.И. Измерение периметра и площади листа дерева // Модернизация системы управления объектами недвижимости: сборник научных трудов I международной научно-практической конференции. 2223.10.2014 г., Пенза: ПГУАС, 2014. С. 89-95.

6. Мазуркин П.М. Коррелятивная вариация: учебное пособие с грифом УМО РАЕ. Йошкар-Ола: Поволжский ГТУ, 2013. 120 с. 
7. Мазуркин П.М. Статистическое моделирование. Эвристикоматематический подход. Йошкар-Ола: МарГТУ, 2001. 100 с.

\section{References}

1. Kudryashova A.I. Descriptive statistics of the shape parameters of leaf-s linden // Problems of recreational spaces, introduction and conservation of flora: Proceedings of the Russian scientific-practical conference with international participation, dedicated to the 25th anniversary of the organization Cheboksary branch of the Main Botanical Garden. Cheboksary, 2014. P. 27-30.

2. Kudryashova A.I. Analysis ontogeny leaf linden // Materials on the scientifically-practical conference "Mathematical modeling in the field of cell biology, biochemistry and biophysics" 25-26 November 2014 Togliatti: Togliatti State University, 2014. P. 137-145.

3. Kudryashova A.I. A method for measuring the perimeter and area of the sheet de roar // III International scientific-practical conference "Actual problems of science and economy: New Challenges and Solutions": public research organization "Science and Management". № 3. 2014. P. 17-20.

4 Kudryashova A.I. A method for measuring the perimeter and area of the sheet in trees // "The experience of the past - look into the future" - 4th Internanative scientific-practical conference of young scientists and students. Materials conference. Tula: TSU, 2014, C. 372-376.

5. Kudryashova A.I. Measuring perimeter and area of the sheet tree // Modernization of property management: a collection of scientifiction of the I International Scientific and Practical Conference. 22-23.10.2014. Penza: PGUAS, 2014. P. 89-95.

6. Mazurkin PM Correlative variation: a tutorial with the stamp of UMO PAE. Yoshkar-Ola: Volga GTU, 2013. 120 p.

7. Mazurkin PM Statistical modeling. Heuristics-mathematical approach. Yoshkar-Ola: MarSTU, 2001. 100 p. 